\title{
Unexamined Assumptions: A Conversation between Arabella Stanger and Simon Ellis
}

\author{
Arabella Stanger, University of Roehampton Dance Department \\ Simon Ellis, C-DaRE University of Coventry
}

Keywords: undergraduate, pedagogy, assessment, screendance, habits

I designed and led a final year undergraduate module in screendance for four years in the Dance Department at Roehampton University in London. The module is an introduction to screendance as choreographic practice and students participated in a number of workshops to help them develop their own screendances. The most recent module blog is online at screendance2015.wordpress.com. During those four years student work was co-marked by Arabella Stanger and me. The following conversation between us explores our experiences of marking the student screendance projects.

- Simon Ellis, April 2016

Simon Ellis: I'd like you to talk about your experiences of assessing undergraduate screendance. Has there been anything you've noticed in particular about the experiences?

Arabella Stanger: There are three things that come to mind. First, it's important to say that helping you grade the screendance module was the first time l've graded choreography of any kind. The second thing is that I'm really glad that my first experience of grading art, in fact, was grading these screendance pieces. The impression I have is that for the majority of these students, the screendance module represented their first opportunity to learn how to make a film. It was their first experience of making in that context; it was my first experience of grading in that context. So everyone was doing something new to them, which leaves room for a certain kind of unorthodoxy. Third, and, I'm not sure if I'm right about this, but it seemed like there was a thread or a character that ran through each of the three cohorts of screendance students that I found to be quite distinctive. Like there were different generations of screendance comrades. 
SE: Can you be more specific about that?

AS: Some ideas repeated themselves within each generation and did not repeat themselves cross generationally.

SE: Would you assume that someone or something influenced the class?

AS: Yes, it could be. Through the works I've seen over the past three years, I observed students dislodged from their habits. Perhaps because when composing for the screen they don't have the same type of technical know-how that they may have when they're working simply with bodies, space and time. On the one hand, this displacement from their usual pattern produces some really exciting and weird work. On the other hand, it might explain shared influences in styles within one cohort: like a sui generis set of habits!

SE: Beyond these shared influences, what are the films that stood out in those years of watching and assessing students' screendance works?

AS: The films that I remember straight away are the ones that involved objects and no humans, or at least a hint of a human. The choreographic work was done through an object or with an object. This is something that screendance as a medium makes possible for these students I think. Non screen-based choreography does not present that possibility in such an easy way.

SE: Yes, even though the possibility still exists. And what is it about those films?

AS: I think again it may be something about the dislodging of habits. These films really attended, in very focused ways, to movement as something that would hold attention. Whereas I think, when working with movement as carried or conveyed by a body - the dancer or the choreographer-some blockages might emerge. By blockages I mean the often unexamined assumptions about what a dancer is, what a dancing body is, and what movement is in a dancing body. The body influences movement. When the body's removed those blockages are removed. When you're working with a medium that's clearly not a dancing body you may have no assumptions. For instance, take a bottle of water: you wouldn't have assumptions about how that bottle of water would carry movement, artistically speaking. There is no dance technique for water bottles. I think this dislodging of habits-couched in an absence of formalised technical expectations-may also take place at the level of spectatorship. When I know I am watching a screendance and the first thing I see is a water bottle, I understand what I see without referring that thing to a set of dancework-specific references. Do you know what I mean? 
SE: I do. Some assumptions fade out. Yet, there is always literacy in the makers. One of the things I observed with students working on their first film, is that lovely tension between them being quite literate-they've spent a lot of time looking at moving image on screens-and at the same time being quite naïve about the conventions of film making and screendance filmmaking. I mention naïvety in the best sense of the word.

AS: You're right. What was also clear every single year that I have seen these films was the strong sense of cinematic genre that invades them. It always catches me by surprise and it delights me, but I think it speaks of that literacy you're talking about: the viewing literacy in cinema as a form, which has its own set of genres. Those genres don't necessarily belong to the body of practices that we might call screendance and they don't necessarily belong to the body of practices we call choreography. But I think a lot of the screendance students over the past few years have invoked those genres, and have positioned their practice more as filmmakers rather than screendance makers. A lot of the films are horror movies for instance. Or they're music videos. That's just two, there are more. There are thrillers as well.

SE: What are the things you find yourself paying attention to when you're watching these student films?

AS: Definitely the opening and closing credits. Because there's no such obvious opportunity to frame your work sort of authorially when you're working with choreography, when it's performed by people in front of other people.

SE: Like a programme note, it is different isn't it?

AS: It is different because with the opening credits it is so deeply integrated into the texture of the work that you're watching. So that always stands out to me. Some of the students have found really inventive ways to play with credits. It may be because it is the first time they've had the opportunity to work with those sort of framing devices.

SE: It's curious because as module leader I only stipulated that if they used music they needed to find royalty free music and then credit it according to the Creative Commons license. We didn't discuss the dramaturgy of credits until after it was clear that the students thought credits were an important marker of presenting a film. Then we talked about what are they, what do they might do to the film, or how is it that they're part of the film. You can think of very clear examples in cinema where credits are designed to something more than communicate production details, like tuning or priming an audience for watching.

AS: This is really a speculation but I wonder if there's another side to it, which is the joy of having a real opportunity to acknowledge your collaborators. I've noticed in these closing credits that 'dancers' or 'performers' are communicated very clearly. 
SE: Are there other things you pay attention to when watching these students' films?

AS: Light and color, which are either brand new or newly discovered elements to play with as a choreographer. A number of the films that I've seen have really been choreographies of light; the more minimalist films have been anyway. Again I think there's something about film as a medium that makes that type of work with light manageable, while a big theatre space would not. The scale of the theatre as known and used by the students is fairly large: a frontal theatre, with a developed technical facility. In comparison, the micro scale of the screen allows elements such as light and colour to be concentrated. That invites a type of play that is not intimidating, or doesn't seem out of the student's reach.

SE: The screen also provides directness in terms of what's in the frame or what's outside of the frame. Which is very different from, or I imagine feels very different for them, from when they are sitting in a theatre looking at a frame that is almost shifting based on their perceptual system, based on their eyes and the way they are seeing.

SE: You haven't taught this module but what would you say, based on your own experiences, to a group of students who were just starting a module in screendance?

AS: You have to watch as much as possible all the time. That will help you figure out what it is that you might want to do. Also, watch the details of what it is that you're watching. Like, the details that are produced by all of the decisions that a filmmaker might make in the course of making a film. I don't think that advice is peculiar to screendance. I think I would give that advice to artists working in any medium.

Another piece of advice not peculiar to screendance is: don't worry about not being experts in or masters of the medium. That lack of expertise can be really helpful in making work that people might be surprised in watching. So in a way, what I would tell them is really paradoxical: 'watch everything' and 'ignore everything'. Then I would say that I am genuinely looking forward to seeing what they come up with because, in my experience, what they come up with is really compelling and delightful and often amusing too.

SE: In talking about your experience with following the screendance students, is there something that you've been reminded of?

AS: The experience of the screendance screenings is a very special one. The audience gathered consists of friends and classmate and peers. This audience is a lot more jubilant, I think, than at other assessment performances for which I've been an audience member. Spectators let loose on a greater scale than they do in other choreographic assessments. I think it is because there's no live dancer who they're worried about interrupting but also there's the feeling of being in the cinema, which is a feeling of being taken away to some other place. 
SE: For the students there are two important differences between the screening and the more traditional format to present choreography. For the most part they've never had that experience of having their work watched by others in that kind of environment. It feels it has a certain kind of vulnerability associated with it. The other thing is, as you've pointed out, that there are no dancers. Makers are not having to talk to dancers, or do lights and technical rehearsals. They've done all of the work. It has been finished days before, or sometimes longer. I think that is quite a shocking experience. In a really, for the most part, positive way.

AS: Maybe that's something that I would mention to them if I met them at the beginning of their module: wait for that moment, the shocking moment of the screening.

\section{Biographies}

Arabella Stanger has a BA in Classical Studies and English at King's College London and an MA in Performance and Culture from Goldsmiths, University of London. She holds a PhD from the Department of Theatre and Performance at Goldsmiths. Arabella's research investigates choreography as cultural practice. Her current interests are shaped in this respect by questions of space and particularly of the implications for dance research of Henri Lefebvre's theorisation of space and society. Her teaching and scholarship is also motivated by the pertinence of choreographic practice to diverse fields of aesthetic and intellectual enquiry, including dance, theatre and performance, visual art, new media, and studies of classical antiquity.

\section{Email: arabella.stanger@roehampton.ac.uk}

Simon Ellis is a choreographer, dancer and film-maker interested in practices and ideas to do with (not necessarily at the same time) power, responsibility, memory, dialogue and screens. His work as a scholar includes understanding ways of knowing through writing, choreography and film, and in supporting the development of practice-asresearch (see practiceasresearchblog.wordpress.com). He is a Senior Research Fellow at the Centre for Dance Research (C-DaRE) at Coventry University, and co-edits IJSD with Harmony Bench.

Email: simonkellis@gmail.com Web: http://www.skellis.net 


\section{References}

Bottles of Note. Dir. Kine Samuline. Prod. Kine Samuline. 2013.

https://vimeo.com/79057466

Our Choice. Dir. Matt Hudson. Prod. Matt Hudson. 2013. https://vimeo.com/81386389 